\title{
Identification and management of congenital parvovirus B19 infection
}

Running title: Congenital parvovirus B19 infections

Authors: Lucy O Attwood ${ }^{1}$, Natasha E Holmes ${ }^{1,2,3}$, Lisa Hui $2,4,5,6$

1Department of Infectious Diseases, Austin Health, Melbourne, Australia

${ }^{2}$ Department of Perinatal Medicine, Mercy Hospital for Women, Melbourne, Australia

${ }^{3}$ Department of Medicine and Radiology, The University of Melbourne, Australia

${ }^{4}$ Department of Obstetrics and Gynaecology, The University of Melbourne, Australia

5Reproductive Epidemiology group, Murdoch Children's Research Institute

${ }^{6}$ Department of Obstetrics and Gynaecology, Northern Health

*Corresponding author

Dr Natasha Holmes

Address: Department of Infectious Diseases, Austin Health, 145 Studley Road,

Heidelberg, Victoria, Australia, 3084

Email: natasha.holmes@austin.org.au Phone:+61 394966676

Bulleted statements: 80

Abstract word count: 161

Main text word count: 3,497

Table count: 1, Figure count: 4

This is the author manuscript accepted for publication and has undergone full peer review but has not been through the copyediting, typesetting, pagination and proofreading process, which may lead to differences between this version and the Version of Record. Please cite this article as doi: $10.1002 / p d .5819$

This article is protected by copyright. All rights reserved. 
Conflict of interest: Nil to declare

Funding statement: LH was funded by a University of Melbourne Faculty of Medicine, Dentistry and Health Sciences Research Fellowship.

This article is protected by copyright. All rights reserved. 


\section{Bulleted Statements}

What's already known about this topic?

- Fetal manifestations of congenital parvovirus B19 virus (B19V) infection include anaemia, hydrops fetalis and fetal death.

- The peak incidence of B19V associated hydrops fetalis is 21-24 weeks gestation during the fetal hepatic stage of haematopoiesis.

What does this study add?

- Routine screening for B19V in pregnancy is not recommended unless there is confirmed B19V exposure or diagnostic workup for fetal anaemia or hydrops is indicated.

- This risk of pregnancy loss is closely related to timing of infection and should inform prenatal counseling, surveillance and specialist follow-up.

\section{Data Availability Statement:}

Research data are not shared 


\begin{abstract}
Parvovirus B19 (B19V) infection is well known for its mild, self-limiting clinical presentations in children, such as erythema infectiosum. Approximately $40 \%$ of women of childbearing age are susceptible to B19V infection. While maternal B19V infection usually has a good prognosis, B19V can cause severe fetal anaemia and pregnancy loss due to its ability to suppress erythroid progenitor cells. Noninvasive ultrasound monitoring for fetal anaemia is usually performed if maternal seroconversion occurs in the first 20 weeks of gestation, with amniocentesis for fetal infection reserved for those who first present with fetal anaemia or hydrops of unknown cause. Intrauterine transfusion is the standard treatment for severe fetal anaemia and is associated with a significant improvement in survival. However, survivors of hydrops fetalis may have a higher rate of long-term neurodevelopmental complications compared with nonhydropic survivors. This review aims to synthesise published data on the diagnosis, surveillance and outcomes of congenital parvovirus infection to assist clinicians in diagnosing and managing this important condition.
\end{abstract}

This article is protected by copyright. All rights reserved. 


\section{Acknowledgements}

We thank Dr Simon Meagher for the provision of the ultrasound images for Figure 4.

LH was funded by a University of Melbourne Faculty of Medicine, Dentistry and Health Sciences Research Fellowship.

This article is protected by copyright. All rights reserved. 


\section{Introduction}

Parvovirus B19 (B19V) is a small single-stranded DNA virus most commonly spread horizontally by respiratory secretions. It can also be transmitted vertically from mother to fetus during pregnancy. ${ }^{1} \mathrm{~B} 19 \mathrm{~V}$ has the characteristic ability to infect the placenta and fetal erythroid precursor cells, potentially leading to devastating complications including fetal anaemia, non-immune hydrops fetalis (NIHF) and intrauterine fetal death (IUFD). In this review, we synthesize the published data on the diagnosis, surveillance and outcomes of fetal parvovirus infection to aid clinicians in counselling and management of maternal infection during pregnancy.

\subsection{Virology and serology}

Parvovirus B19 is the only member of the family Parvoviridae known to be pathogenic in humans. ${ }^{2}$ The B19 virion has several cellular receptors important in its pathogenesis, the most clinically relevant being the globoside or $\mathrm{P}$-antigen $(\mathrm{P}-\mathrm{Ag}){ }^{3} \mathrm{P}-\mathrm{Ag}$ is present on haematopoietic precursors as well as endothelial cells, fetal myocytes, and placental trophoblasts. ${ }^{3-5}$ This characteristic tissue distribution of P-Ag is responsible for the clinical syndromes caused by B19V fetal infections.

Erythropoietin/erythropoietin receptor signaling is essential for B19V tropism and DNA replication. Individuals who have a congenital absence of P-Ag on their erythrocytes demonstrate natural B19V resistance. ${ }^{4}$ Non-haematopoietic tissues that express the P-antigen, such as myocytes, do not permit viral replication. The 
pathogenesis of B19V in these tissues is thought to be due to the toxic accumulation of B19V nonstructural protein (NS1), rather than active viral replication.

Specific B19V IgM antibodies appear seven to twelve days after infection and usually disappear within three to four months. ${ }^{5-8} \mathrm{~B} 19 \mathrm{~V}$-specific IgG is not reliably detectable until about 28 days post exposure. (Figure 1) High-avidity IgG antibodies mediate lifelong immunity and subsequent encounters with B19V boost titres of B19V IgG across a person's lifetime. ${ }^{5}$ Therefore, if a pregnant woman is IgG positive at time of exposure, she is immune and is not at risk of fetal transmission of B19V. 9, 10

\subsection{Epidemiology and transmission}

Infection with parvovirus B19 occurs globally, with increasing seropositivity with age. ${ }^{3,7}$ Approximately $15 \%$ of preschool children, $50 \%$ of young adults and $85 \%$ of the elderly show serologic evidence of past infection. ${ }^{3,7}$ Infection is asymptomatic in 25$50 \%$ of infected individuals. ${ }^{5}$ The susceptibility of women of childbearing age to parvovirus ranges from $26 \%$ to $44 \%$, but is commonly quoted at $40 \% .1,3,8,11-13$ The risk of $\mathrm{B} 19 \mathrm{~V}$ infection during pregnancy is estimated at $1-2 \%$ in endemic periods, rising to $10 \%$ during epidemic periods. ${ }^{3,7,12}$ Seronegative pregnant women, once exposed to the virus, can transmit the infection to the fetus via the placenta in approximately $17-35 \%$ of cases. ${ }^{1,7,14-16}$ Vertical transmission occurs one to three weeks after maternal infection. $3,7,11$

This article is protected by copyright. All rights reserved. 


\subsection{Clinical syndromes of parvovirus B19 in children and adults}

The features of B19V are varied, however, the most common manifestation by far is erythema infectiosum.

\section{$\underline{\text { Acute infection }}$}

Erythema infectiosum (EI, or 'Fifth disease') is the most common clinical manifestation of B19V infection in immunocompetent hosts. Classically, EI affects school-aged children with low-grade fever, malaise and facial rash that gives rise to the name 'slapped cheek syndrome.' The infection is normally self-limiting and resolves within one to two weeks.

Infection with B19V may cause a self-limiting symmetric arthropathy, more frequently in female adults than in children.5, 7 In patients with abnormal erythropoiesis, such as thalassemia or sickle cell anemia, acute B19V can cause a transient aplastic crisis. In sickle cell anaemia, this can be complicated by acute splenic sequestration, hepatic sequestration and acute chest syndrome. ${ }^{17}$

\section{Chronic infection}

In immunocompromised patients, B19V can cause persistent bone marrow suppression manifested by chronic anemia. ${ }^{5}$ About $5 \%$ of adult patients and $10 \%$ of 
children immunosuppressed for haematological malignancies have documented complications from B19V with severe and even lethal cytopenias. ${ }^{5}$

B19V demonstrates tropism for myocytes and B19V has been implicated in a range of myocardial disorders. ${ }^{5}$ Parvovirus B19 has been identified from endomyocardial biopsies and has been associated with myocarditis, dilated cardiomyopathy and left ventricular dysfunction, although a causal link has not been definitively established. ${ }^{18-21}$

On average, $50 \%$ of adult cases of EI have associated joint manifestations that may persist for weeks to months, and sometimes years. ${ }^{5}$ B19V DNA has been detected in synovial tissue specimens in patients with chronic arthritis, although again, a direct causal link has not been clearly identified.

\section{Pathogenesis of maternal-fetal infections}

\subsection{Placental infection}

The presence of P-Ag on the trophoblast layer of the villi provides the pathway by which B19V may be transmitted from an infected mother to the fetus. ${ }^{22} \mathrm{P}-\mathrm{Ag}$ expression by villous trophoblast cells occurs in a gestation-dependent manner. Immunoreactivity for P-Ag is strongest in villous trophoblastic cells of first trimester placentae, with diminished reactivity in second trimester, and a near lack of staining on third trimester placentae. ${ }^{22}$ 


\subsection{Fetal infection}

Unlike the rubella virus, B19V is not teratogenic. However, fetal tissues including haematopoietic cells in the liver, myocardium, endothelial cells, platelets, megakaryocytes and fibroblasts have been demonstrated to express the P-antigen viral receptor. ${ }^{5}$ This correlates with the range of clinical syndromes seen in fetal infections.

The fetal liver acts as the primary haematopoietic organ from nine to twenty four weeks gestation. The second trimester is also the period of the most rapid increase in red cell mass in the fetus, increasing by more than 30 -fold. However, the half-life of fetal red cells produced at this gestation is relatively short at 45-70 days. ${ }^{23}$ (Figure 2) Thus, the fetus is exquisitely vulnerable to any pause in red cell production in second trimester. ${ }^{1}$ This risk is greatly decreased in the third trimester, when fetal haematopoiesis has shifted to bone marrow and the lifespan of red blood cells is increased.

The observed risk of B19V-induced NIHF ranges from 3.9 - 11.9\%, with the peak incidence between 21 and 24 weeks of gestation. 3, 7,13,24 The interval between B19V infection and development of NIHF usually ranges from two to six weeks. ${ }^{3,} 7$ Pregnancy outcomes after maternal infection are discussed in further detail below.

\section{Diagnosis and clinical management}

This article is protected by copyright. All rights reserved. 


\subsection{Diagnosis of maternal infection}

No national society currently recommends routine antenatal serological screening for B19V immune status. ${ }^{8-10}$ Women are most commonly tested for parvovirus B19 infection after a known exposure, or when ultrasonography reveals hydrops fetalis or fetal anaemia of unknown cause.

The diagnosis of maternal infection relies on antibody detection, though viremia detection with PCR is available. ${ }^{7}$ Figure 3 demonstrates the role of serology in guiding clinical management of the pregnant woman. Pregnant women exposed to B19V should have serologic screening performed as soon as possible after exposure to determine if they are at risk of acute infection. ${ }^{9,} 10$ If B19V IgG is present and IgM is negative, the woman is immune and should be reassured that she will not develop infection.9, 10 If both B19V IgG and IgM are negative, the woman is susceptible to infection. As infection can be asymptomatic, susceptible women who have had a documented exposure should be re-tested for seroconversion in two to four weeks. ${ }^{3}$

A positive IgM result is evidence of recent infection, but a negative result must be interpreted in the context of the presumed time since exposure. Maternal serology can be misleading if checked within seven days of exposure to an infectious contact as IgG and IgM could both be negative at this stage. ${ }^{6}$ The sensitivity of IgM antibody detection at eight to twelve weeks after maternal infection is reported to vary from 63 to $70 \%$, implicating a substantial number of false negative results. ${ }^{3,7,13}$ Thus the absence of IgM 
cannot exclude fetal B19V infection two to three months before testing. At the time of clinically overt NIHF, IgM levels may already have become low or even undetectable.3,14

Polymerase chain reaction (PCR) on plasma for maternal B19V DNA can improve the diagnostic accuracy early in the course of maternal infection. ${ }^{3,6,13}$ B19 viraemia occurs as early as five to ten days after exposure, before any change in serology is detected (see Figure 1). Viraemia can be detected for approximately seven days in immunocompetent individuals, prior to the onset of symptoms (if they occur). However, it is generally unlikely to be positive after onset of maternal symptoms. ${ }^{8}$ In a study of 72 pregnancies complicated by B19V infection, IgM serology correctly diagnosed $94.1 \%$ of B19V infections, compared with 96.3\% correctly diagnosed using B19V PCR. ${ }^{14}$ If a pregnant patient has a history of recent parvovirus exposure and initial serologies are negative, maternal B19V PCR screening can help achieve maximum diagnostic sensitivity. However, the clinical utility of PCR testing is low and not routinely used, since maternal diagnosis is not usually time critical and waiting for confirmatory serological testing is still required.

There is no antiviral therapy or passive immunoglobulin treatment for B19V infection and no therapy to prevent fetal infection after maternal exposure. Management of congenital B19V infection thus relies on secondary prevention of severe fetal consequences due to anaemia.

\subsection{Invasive prenatal diagnosis of fetal infection}

This article is protected by copyright. All rights reserved. 
Amniocentesis for PCR of B19V DNA is the method of choice to diagnosis fetal parvovirus infection when investigating a fetus that presents with hydrops of unknown cause. ${ }^{25}$ Maternal serology in this clinical presentation is only useful if both IgG and IgM are negative, which excludes maternal and hence fetal B19V infection. As discussed above, other combinations of maternal serology results are compatible fetal infection, including an IgG positive/IgM negative result. Whilst PCR for B19V can be performed on both fetal cord blood or amniotic fluid, amniotic fluid has a higher detection rate and is less invasive than cord blood sampling. ${ }^{15}$ Fetal serology is rarely used diagnostically as the fetal immune system is immature and does not mount predictable IgG/IgM immune response. $.3,6,25$ Detection of B19V-specific IgM in fetal blood only has a sensitivity of $29 \%$, and percutaneous fetal blood sampling carries a $1 \%$ fetal loss rate. ${ }^{3}$

It is much more common for women to present with B19V seroconversion with a normal fetal ultrasound. These women are usually managed noninvasively with ultrasound monitoring for fetal anaemia rather than amniocentesis.

\subsection{Non-invasive fetal monitoring with ultrasound}

If a maternal B19V infection has been diagnosed before twenty weeks gestation, referral for specialist assessment should be made as infection in the first half of pregnancy confers the highest risk of fetal anaemia. The fetus is non-invasively monitored for fetal anaemia with ultrasound every one to two weeks for up to 12 weeks after infection.7, 9, 10 Anaemia is detected using Doppler measurement of the middle cerebral artery (MCA) peak systolic velocity (PSV), which has good diagnostic accuracy 
in identifying anaemic fetuses using the standard threshold of MCA PSV > 1.5 MoMs from 18 weeks gestation. $1,3,14,18,26$

The ultrasound measurement of the MCA PSV is obtained by obtaining an axial view of the circle of Willis. We recommend the technique as described by the International Society of Ultrasound in Obstetric and Gynaecology guidelines. ${ }^{27}$ The risk of anemia is highest in fetuses with a pre-transfusion peak systolic velocity of $\geq 1.5 \mathrm{MoM}$, though lower thresholds (eg. $1.29 \mathrm{MoM}$ ) have higher sensitivity, for lower specificity. ${ }^{26}$, ${ }^{28}$ A multicentre study of MCA PSV in 32 at risk fetuses (due to maternal parvovirus infection) demonstrated that parvovirus infection can be detected noninvasively by Doppler ultrasonography. Cordocenteses performed in 16 out of 17 fetuses with MCA PSV of $>1.50$ MoM demonstrated anaemia. ${ }^{29}$ PSV for the prediction of anaemia caused by parvovirus infection in this study had a sensitivity of $94.1 \%$ with a specificity of $93.3 \% .^{29}$

The classic MCA PSV reference charts developed by Mari et al date from 18 weeks. ${ }^{26}$ However, adaptations to extrapolate normal MCA PSV ranges to earlier gestations exist. The frequency of surveillance should be increased to weekly MCA PSV once the option of fetal transfusion becomes a realistic option. If hydrops or evidence of fetal anaemia on MCA PSV monitoring develops, referral should be made to a specialist capable of fetal blood sampling and intrauterine transfusion. ${ }^{9,10}$ (Figure 3)

Early signs of NIHF include fetal ascites and cardiomegaly. In advanced stages, generalized oedema, pericardial effusion and a thick, oedematous placenta can be 
found.6, 30, 31 Figure 4 demonstrates a fetus at 22 weeks gestation with hydrops exhibiting cardiomegaly, pericardial effusion and ascites. The placental changes are thought to be responsible for the occasional maternal complication of 'mirror syndrome,' a pre-eclampsia-like syndrome with edema, hypertension, proteinuria and maternal anemia and reflects the signs present in the fetus., 7 Other reported ultrasound signs of parvovirus B19 infection include echogenic bowel, meconium peritonitis, first trimester increased nuchal translucency, amniotic fluid abnormalities and myocardial dysfunction. ${ }^{32-36}$

\subsection{Other clinical manifestations of fetal infection}

\section{Fetal myocarditis}

Myocarditis is a known complication of fetal B19V and may contribute to hydrops and fetal death in some cases. ${ }^{37-40}$ Wang et al. reported the presence of B19V DNA in cardiac tissues at autopsies of 29 infants born to mothers positive for parvovirus. ${ }^{41}$ Seventeen per cent were positive for parvovirus while all thirty controls were negative. ${ }^{41}$ Fetal cases of B19V with massive endocardial fibroelastosis have also been reported without anaemia, some of which persisted into the newborn period. ${ }^{42,43}$

Thrombocytopenia

This article is protected by copyright. All rights reserved. 
Severe thrombocytopenia has been described in approximately $40 \%$ of parvovirus-infected fetuses with NIHF.44 There is a large range of thrombocytopenia described, from $2 \times 10^{9} / \mathrm{L}$ to $155 \times 10^{9} / \mathrm{L} .{ }^{45}, 46$ The largest published series by de Haan et al. described platelet counts less than $50 \times 10^{\wedge} 9 / \mathrm{L}$ in $46 \%$ of B19V infected fetuses, though spontaneous fetal haemorrhage was not observed. ${ }^{44}$ While the risk of fetal haemorrhage due to thrombocytopenia is not possible to quantify, anecdotally some clinicians prophylactically transfuse platelets at the time of red cell transfusions for fetuses with B19V-mediated anaemia. In a study of 11 pregnant women, two fetuses with severe thrombocytopenia (platelet count of 2.0 and $24 \times 10^{9} / \mathrm{L}$ ) died secondary to exsanguination from umbilical cord puncture. Clinicians should be aware of the risk of severe thrombocytopenia and consider platelet transfusion during cordocentesis if the platelet count is $<50 \times 10^{9} / \mathrm{L}^{46}$

\subsection{Management of anaemia and NIHF}

Intrauterine transfusions (IUT) of red blood cells were pioneered for fetal hemolytic disease due to Rhesus alloimmunisation and they are now standard treatment for a variety of causes of fetal anaemia. ${ }^{47}$ Although never studied in randomised trials, observational studies have clearly demonstrated that IUT in severely anaemic fetus with B19V infection improves survival. IUT has been shown to reduce the mortality rate from about 50 to $18 \%$, with most non-hydropic fetuses usually requiring only a single transfusion. ${ }^{5,} 6$ In a meta-analysis of fourteen studies including 1,436 cases of fetal B19V infection, the survival rate of transfused fetuses was $82 \%$ compared with 
$55 \%$ without transfusion. ${ }^{48}$ In contrast to the progressive nature of Rhesus disease, the natural history of anaemia due to parvovirus is resolution as fetal haematopoiesis shifts from the liver to the bone marrow in the third trimester. ${ }^{6}$ The performance of MCA PSV for prediction of anaemia in transfused fetuses does decline ${ }^{49}$ but ongoing monitoring after IUT with MCA PSV is still warranted until the risk of post-procedure complications and recurrent anaemia are past.

The earliest gestation at which an IUT can be offered will be dependent on the expertise and facilities of the treating centre, as well as individual clinical factors such as placental location and technical access. IUT $<20$ weeks gestation is possible via the intravascular or intraperitoneal routes and has been performed as early as first trimester. ${ }^{50,51}$ The commencement of intensive surveillance for fetal infection will be tailored to the gestation at which the fetal centre is able to offer fetal intervention with IUT.

As discussed above, thrombocytopenia may accompany the severe anaemia of fetal B19V, potentially increasing the IUT procedure-related risk of exsanguination. ${ }^{6,46}$ Although concurrent intrauterine platelet transfusion can be performed, potential complications include fluid overload, thrombosis and concomitant cardiac failure. These risks must be weighed up against the low overall incidence of fetal bleeding complications in B19V infection, though severity of thrombocytopenia should be considered..$^{3,44,46}$ 


\subsection{Postnatal management}

No specific postnatal investigation is indicated in infants that did not have evidence of fetal anaemia or other ultrasound features of congenital B19V infection. Infants that had fetal anaemia requiring IUT, myocarditis or hydrops should have paediatric review and follow up according to local practice.

\section{Pregnancy outcomes}

\subsection{Perinatal outcomes}

Whilst the estimated contribution of parvovirus infection to the overall burden of fetal loss is low ( $0.1 \%$ up to $0.8 \%$ during epidemics), ${ }^{52}$ maternal B19V infection has been found to increase the risk of fetal loss (odds ratio (OR) 2.68), spontaneous abortion (OR 2.42) and stillbirth (OR 3.53) when compared with uninfected pregnant women. 53

Hydrops is the main determinant of mortality and adverse perinatal outcome in B19V infection. Twenty-nine per cent of hydropic fetuses suffered perinatal death compared to $4 \%$ of non-hydropic fetuses in one meta-analysis. ${ }^{1}$ However, it should be noted that hydrops can resolve spontaneously with an apparently normal infant at delivery, although the rate of spontaneous resolution is uncertain. ${ }^{1,54}$ Spontaneous resolution of anaemia without the need of IUT occurred in $5.2 \%$ of cases in fetuses affected by hydrops compared to resolution in $49.6 \%$ of fetuses not affected by hydrops in one study. ${ }^{1}$ Bascietto et al. have summarized the overall outcomes in B19V congenital 
infections, depending on the absence or presence of hydrops. ${ }^{1}$ This is presented in Table 1.

Gestation at infection is also a main determinant of pregnancy loss. A prospective study of B19V infection in pregnant woman based on serological studies calculated an overall 6\% miscarriage/fetal death rate (64/1018). ${ }^{24}$ All of these losses occurred in cases of infection prior to 20 weeks gestation despite targeted ultrasound examination following serological diagnosis. The miscarriage rate in women diagnosed in first trimester was $13 \%$, and this rate decreased to $9 \%$ for infections diagnosed at 13-20 weeks and $0 \%$ after 20 weeks. The majority of fetal deaths (80\%) occurred within 4 weeks of infection (median 3 weeks) and the highest risk of fetal death occurred with maternal infection between 9-16 weeks. ${ }^{24}$ It is unclear whether fetal transfusions were offered before 20 weeks at the study centre, so the higher rates of fetal deaths may also reflect difficulties addressing suspected fetal anaemias based on ultrasound surveillance. This prospective study supports the existing literature that indicates minimal risk if infection occurs in the second half of pregnancy. ${ }^{14,24,30,55,56}$ However, it should be noted that there were four stillbirths in this study attributed to B19V infection between 22 and 24 weeks gestation. This was in a cohort of 96 pregnancies diagnosed with acute maternal B19V infection between 21 and 24 weeks. ${ }^{24}$ B19V has been detected in stillbirths up to 41 weeks gestation.3, 7,57-59 In a case series of stillbirths born after 22 weeks, parvovirus was detected in 13 of the $92(14 \%)$ cases. ${ }^{60}$ Only two of the parvovirus B19 DNA-positive cases were hydropic. ${ }^{60}$ While it is not possible to 
predict the risk of third trimester fetal death after maternal infection from these case control studies, it does suggest a potential role for B19V in some unexpected stillbirths.

\subsection{Long term fetal complications}

As well as the prenatal complications of fetal anaemia, long-term neurological sequlae of congenital B19V infection have also been reported. Case reports of hydropic survivors describe ventriculomegaly, polymicrogyria and heterotopia among the range of central nervous system anomalies. ${ }^{61,62}$ In a systematic review, the prevalence of abnormal brain imaging was $9.8 \%$ in fetuses with hydrops compared to $0 \%$ in those without hydrops. ${ }^{1}$ In this review, the risk of abnormal neurodevelopmental outcome was almost $10 \%$ in children who had fetal hydrops due to B19V infection. ${ }^{1}$

Neurodevelopmental problems in the absence of structural brain lesions may also occur after intrauterine transfusions in up to $12.5 \%$ of children. ${ }^{63}$ Neurodevelopmental delays have been measured as ranging from mild cognitive delay, to mild fine motor impairment, to severe developmental delay and neurological abnormalities including ataxia, hypertonia and cerebral palsy, though severe complications are rare. ${ }^{64-66}$ It is not clear whether the pathogenesis of neurodevelopmental abnormalities is severe fetal anaemia, hypoxia/ischaemia, direct viral effect, or complications of IUT.

This article is protected by copyright. All rights reserved. 
Isolated case reports and case series have also described gastrointestinal complications associated with parvovirus B19 infection, particularly hyperechogenic bowel and meconium peritonitis. ${ }^{16,32-34}$ Congenital hypoplasia of the abdominal muscles in newborns after intrauterine B19V infection as a result of ascites has also been reported. 35,36

\section{Summary}

While universal maternal serological screening is not a routine part of prenatal care, accurate identification and treatment of fetuses affected by congenital B19V infection has been shown to improve perinatal outcomes. Early stratification of fetal risk by gestational age and commencement of fetal monitoring for anaemia when IUT is a feasible option is vital as the outcome of congenital B19V infection is excellent if managed prior to the onset of hydrops.

There are still many future research questions required to be answered in order to improve the identification and management of congenital parvovirus B19 infection. These include improved strategies to prevent maternal infection and more data on the long-term outcome of neonates born after an intrauterine B19V infection. At present, however, maternal serology, fetal ultrasonography and timely IUT are the gold standards to manage this eminently treatable congenital infection. 


\section{References:}

1. Bascietto F, Liberati M, Murgano D, et al. Outcome of fetuses with congenital parvovirus B19 infection: systematic review and meta-analysis. Ultrasound Obstet Gynecol. 2018;52(5):569-76.

2. Heegaard ED, Brown KE. Human parvovirus B19. Clin Microbiol Rev.

2002;15(3):485-505.

3. de Jong EP, Walther FJ, Kroes AC, Oepkes D. Parvovirus B19 infection in pregnancy: new insights and management. Prenat Diagn. 2011;31(5):419-25.

4. Brown KE, Hibbs JR, Gallinella G, et al. Resistance to parvovirus B19 infection due to lack of virus receptor (erythrocyte P antigen). N Engl J Med. 1994;330(17):1192-6.

5. Broliden K, Tolfvenstam T, Norbeck O. Clinical aspects of parvovirus B19 infection. J Intern Med. 2006;260(4):285-304.

6. Brennand J, Cameron A. Fetal anaemia: diagnosis and management. Best Pract Res Clin Obstet Gynaecol. 2008;22(1):15-29.

7. Dijkmans AC, de Jong EP, Dijkmans BA, et al. Parvovirus B19 in pregnancy: prenatal diagnosis and management of fetal complications. Curr Opin Obstet Gynecol. 2012;24(2):95-101.

8. Parvovirus. 2014. In: Management of Perinatal Infections [Internet]. Sydney: Australian Society for Infectious Diseases (ASID); [51 - 5].

9. Gynecologists ACoOa. Practice bulletin no. 151: Cytomegalovirus, parvovirus B19, varicella zoster, and toxoplasmosis in pregnancy. Obstet Gynecol. 2015;125(6):1510-25.

10. Crane J, Mundle W, Boucoiran I, COMMITTEE MFM. Parvovirus B19 infection in pregnancy. J Obstet Gynaecol Can. 2014;36(12):1107-16.

11. Gilbert GL. Parvovirus B19 infection and its significance in pregnancy. Commun Dis Intell. 2000;24 Suppl:69-71.

12. Mossong J, Hens N, Friederichs V, et al. Parvovirus B19 infection in five European countries: seroepidemiology, force of infection and maternal risk of infection. Epidemiol Infect. 2008;136(8):1059-68.

13. Enders $\mathrm{M}$, Klingel $\mathrm{K}$, Weidner $\mathrm{A}$, et al. Risk of fetal hydrops and non-hydropic late intrauterine fetal death after gestational parvovirus B19 infection. J Clin Virol. 2010;49(3):163-8.

14. Bonvicini F, Puccetti C, Salfi NC, et al. Gestational and fetal outcomes in B19 maternal infection: a problem of diagnosis. J Clin Microbiol. 2011;49(10):3514-8.

15. Bonvicini F, Manaresi E, Gallinella G, et al. Diagnosis of fetal parvovirus B19 infection: value of virological assays in fetal specimens. BJOG. 2009;116(6):813-7.

16. Puccetti C, Contoli M, Bonvicini F, et al. Parvovirus B19 in pregnancy: possible consequences of vertical transmission. Prenat Diagn. 2012;32(9):897-902.

17. Smith-Whitley K, Zhao H, Hodinka RL, et al. Epidemiology of human parvovirus B19 in children with sickle cell disease. Blood. 2004;103(2):422-7.

18. Kühl U, Pauschinger M, Seeberg B, et al. Viral persistence in the myocardium is associated with progressive cardiac dysfunction. Circulation. 2005;112(13):1965-70. 
19. Tschöpe C, Bock CT, Kasner M, et al. High prevalence of cardiac parvovirus B19 infection in patients with isolated left ventricular diastolic dysfunction. Circulation. 2005;111(7):879-86.

20. Stewart GC, Lopez-Molina J, Gottumukkala RV, et al. Myocardial parvovirus B19 persistence: lack of association with clinicopathologic phenotype in adults with heart failure. Circ Heart Fail. 2011;4(1):71-8.

21. Vigneswaran TV, Brown JR, Breuer J, Burch M. Parvovirus B19 myocarditis in children: an observational study. Arch Dis Child. 2016;101(2):177-80.

22. Jordan JA, DeLoia JA. Globoside expression within the human placenta. Placenta. 1999;20(1):103-8.

23. Hoffman R, Benz Jr EJ, Silberstein LE, et al. Hematology: Basic Principles and Practice. 5th ed. ed. Philadelphia: Churchill Livingstone, An Imprint of Elsevier; 2009.

24. Enders M, Weidner A, Zoellner I, et al. Fetal morbidity and mortality after acute human parvovirus B19 infection in pregnancy: prospective evaluation of 1018 cases. Prenat Diagn. 2004;24(7):513-8.

25. Giorgio E, De Oronzo MA, Iozza I, et al. Parvovirus B19 during pregnancy: a review. J Prenat Med. 2010;4(4):63-6.

26. Mari G, Deter RL, Carpenter RL, et al. Noninvasive diagnosis by Doppler ultrasonography of fetal anemia due to maternal red-cell alloimmunization.

Collaborative Group for Doppler Assessment of the Blood Velocity in Anemic Fetuses. N Engl J Med. 2000;342(1):9-14.

27. Bhide A, Acharya G, Bilardo CM, et al. ISUOG practice guidelines: use of Doppler ultrasonography in obstetrics. Ultrasound Obstet Gynecol. 2013;41(2):233-239.

28. Delle Chiaie L, Buck G, Grab D, Terinde R. Prediction of fetal anemia with Doppler measurement of the middle cerebral artery peak systolic velocity in pregnancies complicated by maternal blood group alloimmunization or parvovirus B19 infection. Ultrasound Obstet Gynecol. 2001;18(3):232-6.

29. Cosmi E, Mari G, Delle Chiaie L, et al. Noninvasive diagnosis by Doppler ultrasonography of fetal anaemia resulting from parvovirus infection. Am J Obstet Gynecol. 2002;187(5):1290-1293.

30. Ornoy A, Ergaz Z. Parvovirus B19 infection during pregnancy and risks to the fetus. Birth Defects Res. 2017;109(5):311-23.

31. Hartge DR, Weichert J, Gembicki M, Krapp M. Confirmation of etiology in fetal hydrops by sonographic evaluation of fluid allocation patterns. Eur J Obstet Gynecol Reprod Biol. 2015;195:128-32.

32. Yaron Y, Hassan S, Geva E, et al. Evaluation of fetal echogenic bowel in the second trimester. Fetal Diagn Ther. 1999;14(3):176-80.

33. Schild RL, Plath $\mathrm{H}$, Thomas $\mathrm{P}$, et al. Fetal parvovirus B19 infection and meconium peritonitis. Fetal Diagn Ther. 1998;13(1):15-8.

34. Zerbini M, Gentilomi GA, Gallinella G, et al. Intra-uterine parvovirus B19 infection and meconium peritonitis. Prenat Diagn. 1998;18(6):599-606. 
35. Macé G, Audry G, Cortey A, et al. Congenital hypoplasia of the abdominal wall muscles following fetal ascites due to parvovirus B19 infection. Ultrasound Obstet Gynecol. 2011;37(4):497-8.

36. Travan L, Naviglio S, Cont G, et al. Isolated hypoplasia of abdominal wall muscles associated with fetal ascites. Congenit Anom (Kyoto). 2016;56(4):184-6.

37. Marton T, Martin WL, Whittle MJ. Hydrops fetalis and neonatal death from human parvovirus B19: an unusual complication. Prenat Diagn. 2005;25(7):543-5.

38. Rogers BB, Mark Y, Oyer CE. Diagnosis and incidence of fetal parvovirus infection in an autopsy series: I. Histology. Pediatr Pathol. 1993;13(3):371-9.

39. White FV, Jordan J, Dickman PS, Knisely AS. Fetal parvovirus B19 infection and liver disease of antenatal onset in an infant with Ebstein's anomaly. Pediatr Pathol Lab Med. 1995;15(1):121-9.

40. Fishman SG, Pelaez LM, Baergen RN, Carroll SJ. Parvovirus-mediated fetal cardiomyopathy with atrioventricular nodal disease. Pediatr Cardiol. 2011;32(1):84-6.

41. Wang X, Zhang G, Han M, et al. Investigation of parvovirus B19 in cardiac tissue from patients with congenital heart disease. Chin Med J (Engl). 1999;112(11):995-7.

42. Hichijo A, Morine M. A case of fetal parvovirus b19 myocarditis that caused terminal heart failure. Case Rep Obstet Gynecol. 2014;2014:463571.

43. von Kaisenberg CS, Bender G, Scheewe J, et al. A case of fetal parvovirus B19 myocarditis, terminal cardiac heart failure, and perinatal heart transplantation. Fetal Diagn Ther. 2001;16(6):427-32.

44. de Haan TR, van den Akker ES, Porcelijn L, et al. Thrombocytopenia in hydropic fetuses with parvovirus B19 infection: incidence, treatment and correlation with fetal B19 viral load. BJOG. 2008;115(1):76-81.

45. Simms RA, Liebling RE, Patel RR, et al. Management and outcome of pregnancies with parvovirus B19 infection over seven years in a tertiary fetal medicine unit. Fetal Diagn Ther. 2009;25(4):373-8.

46. Segata M, Chaoui R, Khalek N, et al. Fetal thrombocytopenia secondary to parvovirus infection. Am J Obstet Gynecol. 2007;196(1):61.e1-61.e614. doi:10.1016/j.ajog.2006.08.041

47. Castleman JS, Kilby MD. Red cell alloimmunization: A 2020 update. Prenat Diagn. 2020.

48. von Kaisenberg CS, Jonat W. Fetal parvovirus B19 infection. Ultrasound Obstet Gynecol. 2001;18(3):280-8.

49. Martinez-Portilla RJ, Lopez-Felix J, Hawkins-Villareal A, et al. Performance of fetal middle cerebral artery peak systolic velocity for prediction of anemia in untransfused and transfused fetuses: systematic review and meta-analysis. Ultrasound Obstet Gynecol. 2019;54(6):722-31.

50. Kempe A, Rösing B, Berg C, et al. First-trimester treatment of fetal anemia secondary to parvovirus B19 infection. Ultrasound Obstet Gynecol. 2007;29(2):226-8.

51. Hellmund A, Geipel A, Berg C, et al. Early Intrauterine Transfusion in Fetuses with Severe Anemia Caused by Parvovirus B19 Infection. Fetal Diagn Ther. 2018;43(2):129-37. 
52. Lassen J, Jensen AK, Bager P, et al. Parvovirus B19 infection in the first trimester of pregnancy and risk of fetal loss: a population-based case-control study. Am J Epidemiol. 2012;176(9):803-7.

53. Xiong YQ, Tan J, Liu YM, et al. The risk of maternal parvovirus B19 infection during pregnancy on fetal loss and fetal hydrops: A systematic review and metaanalysis. J Clin Virol. 2019;114:12-20.

54. Rodis JF, Borgida AF, Wilson M, et al. Management of parvovirus infection in pregnancy and outcomes of hydrops: a survey of members of the Society of Perinatal Obstetricians. Am J Obstet Gynecol. 1998;179(4):985-8.

55. Miller E, Fairley CK, Cohen BJ, Seng C. Immediate and long term outcome of human parvovirus B19 infection in pregnancy. Br J Obstet Gynaecol. 1998;105(2):1748.

56. Yaegashi N, Niinuma T, Chisaka $\mathrm{H}$, et al. The incidence of, and factors leading to, parvovirus B19-related hydrops fetalis following maternal infection; report of 10 cases and meta-analysis. J Infect. 1998;37(1):28-35.

57. Morey AL, Keeling JW, Porter HJ, Fleming KA. Clinical and histopathological features of parvovirus B19 infection in the human fetus. Br J Obstet Gynaecol. 1992;99(7):566-74.

58. Žegarac Ž, Duić Ž, Borovečki A. Recent parvovirus B19 infection in late pregnancy. Int J Gynaecol Obstet. 2013;122(3):262-3.

59. Tolfvenstam T, Papadogiannakis N, Norbeck O, et al. Frequency of human parvovirus B19 infection in intrauterine fetal death. Lancet. 2001;357(9267):1494-7.

60. Norbeck O, Papadogiannakis N, Petersson K, et al. Revised clinical presentation of parvovirus B19-associated intrauterine fetal death. Clin Infect Dis. 2002;35(9):10328.

61. Pistorius LR, Smal J, de Haan TR, et al. Disturbance of cerebral neuronal migration following congenital parvovirus B19 infection. Fetal Diagn Ther. 2008;24(4):491-4.

62. Schulert GS, Walsh WF, Weitkamp JH. Polymicrogyria and congenital parvovirus b19 infection. AJP Rep. 2011;1(2):105-10.

63. Lindenburg IT, van Klink JM, Smits-Wintjens VE, et al. Long-term neurodevelopmental and cardiovascular outcome after intrauterine transfusions for fetal anaemia: a review. Prenat Diagn. 2013;33(9):815-22.

64. De Jong EP, Lindenburg IT, van Klink JM, et al. Intrauterine transfusion for parvovirus B19 infection: long-term neurodevelopmental outcome. Am J Obstet Gynecol. 2012;206(3):204.e1-5.

65. Nagel HT, de Haan TR, Vandenbussche FP, et al. Long-term outcome after fetal transfusion for hydrops associated with parvovirus B19 infection. Obstet Gynecol. 2007;109(1):42-7.

66. Lindenburg IT, van Kamp IL, van Zwet EW, et al. Increased perinatal loss after intrauterine transfusion for alloimmune anaemia before 20 weeks of gestation. BJOG. 2013;120(7):847-52. 
67. Brown KE, Young NS. Parvovirus B19 infection and hematopoiesis. Blood Rev. 1995;9(3):176-82.

68. Michał Komorniczak (Poland), released under Creative Commons 3.0.

Attribution-ShareAlike (CC BY-SA 3.0) licence based on: B.F. Rodak, G.A. Fritsma. K. Doig: Hematology: Clinical Principles and Applications. 3rd ed.. Saunder, 2007. ISBN 9781416030065 Figure 7-1 R. 


\section{Figure Legends}

Figure 1 - Virological, immunological and clinical course after acute B19 infection in a normal individual*

${ }^{*}$ Reproduced from Brown et al. ${ }^{67}$ with permission from Elsevier.

This article is protected by copyright. All rights reserved. 
Figure 2 - Prenatal and postnatal stages of haematopoiesis*

*Illustration by Michał Komorniczak68 (Poland), released under Creative Commons 3.0. Attribution-ShareAlike (CC BY-SA 3.0)

This article is protected by copyright. All rights reserved. 
Figure 3 - Evaluation and management of women exposed to parvovirus B19 during pregnancy

+ If IUT is an option before 18 weeks, start weekly USS

Abbreviations - B19V: Parvovirus B19, w: weeks, MCA: middle cerebral artery, IUT:

intrauterine transfusion

This article is protected by copyright. All rights reserved. 
Figure 4 - Fetus at 22 weeks gestation with hydrops due to parvovirus infection, exhibiting (A) cardiomegaly and pericardial effusion, and (B) ascites*

*Images courtesy of Dr Simon Meagher (University of Melbourne, Mercy Hospital for Women and Monash Ultrasound for Women)

This article is protected by copyright. All rights reserved. 
Clinical

Features

Hematological Changes

B19 DNA
B19 Serology
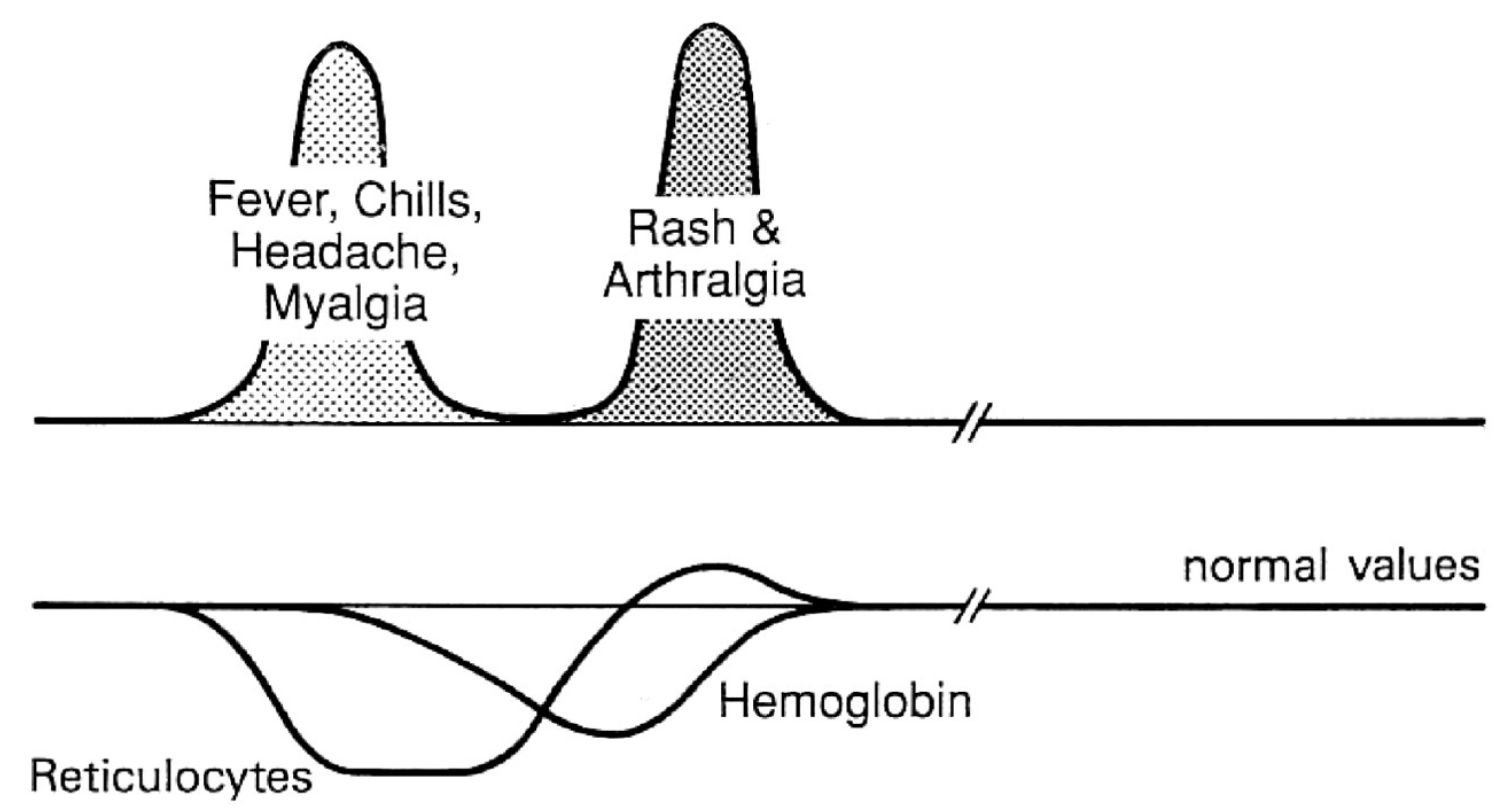

Dot blot

$$
\text { PCR }
$$

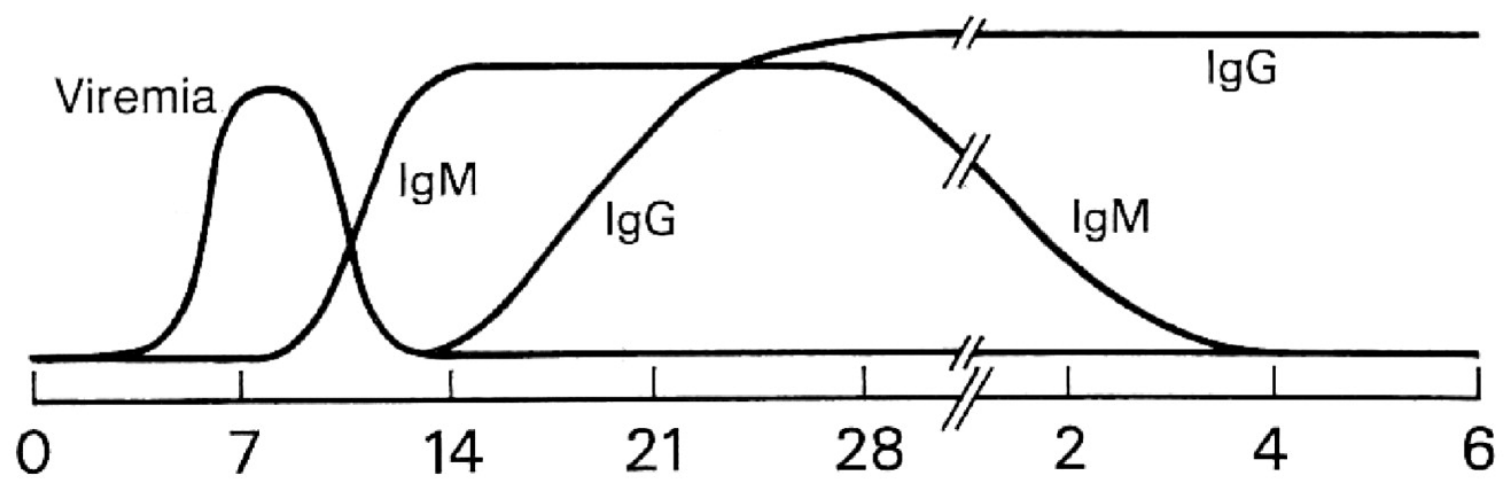

This article is protected by copyright. All righayyserved.

Months 


\section{HEMATOPOIESIS•}
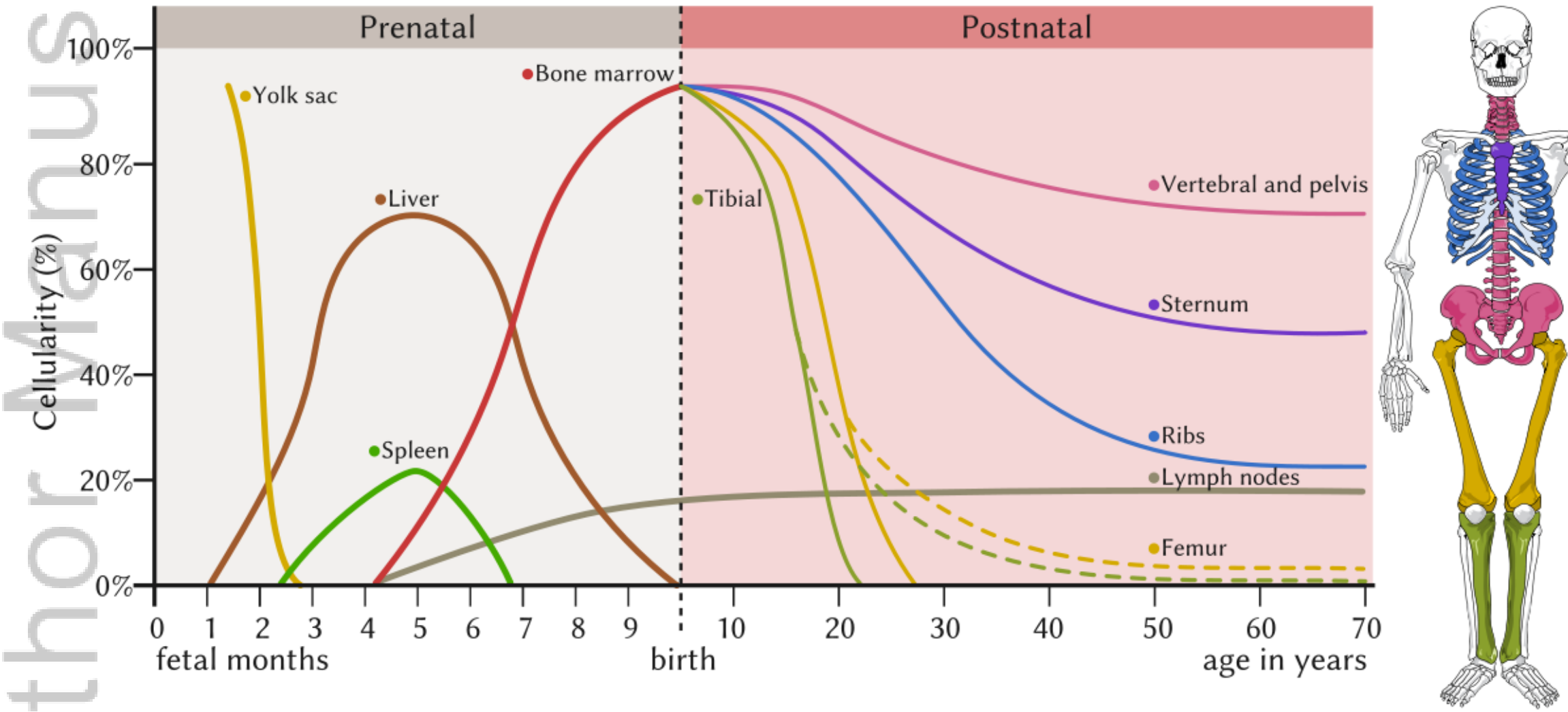

This article is protected by copyright. All rights reserved. 


\section{Susceptible \\ Repeat serology after 2-4w} or if symptoms occur

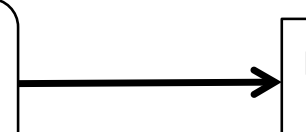

Maternal Serology

(Within 4 w of exposure)

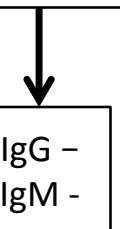

$\lg G+/-$

$\lg \mathrm{M}+$

Immune

No risk infection

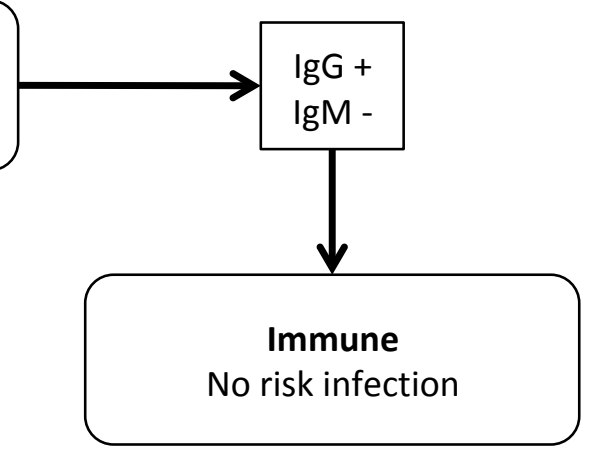

No

infection

Maternal infection $<9 w$

- Ultrasound at initial assessment

- Ultrasound fortnightly from $\mathbf{1 2 w}$ until $12 w$ post maternal infection

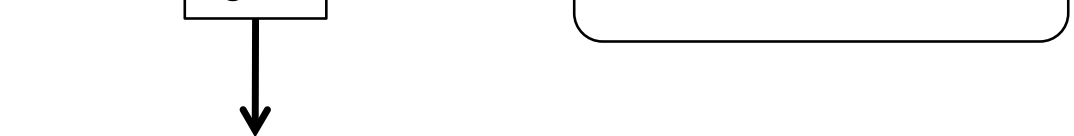

\section{Fetal surveillance} ultrasonography

Maternal infection 9-20w

- Ultrasound at initial assessment

- Ultrasound fortnightly until $\mathbf{1 8 w}$, then weekly until $12 w$ post maternal infection ${ }^{\dagger}$

Ultrasound features of fetal B19V

- MCA >1.5 MoM

- Hydrops fetalis

- Cardiomegaly, endocardial fibroelastosis

- Echogenic bowel, meconium peritonitis

- Enlarged nuchal translucency

- Placentomegaly

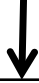

\section{Consider}

This article is protected by copyright. All/rights reserved. 

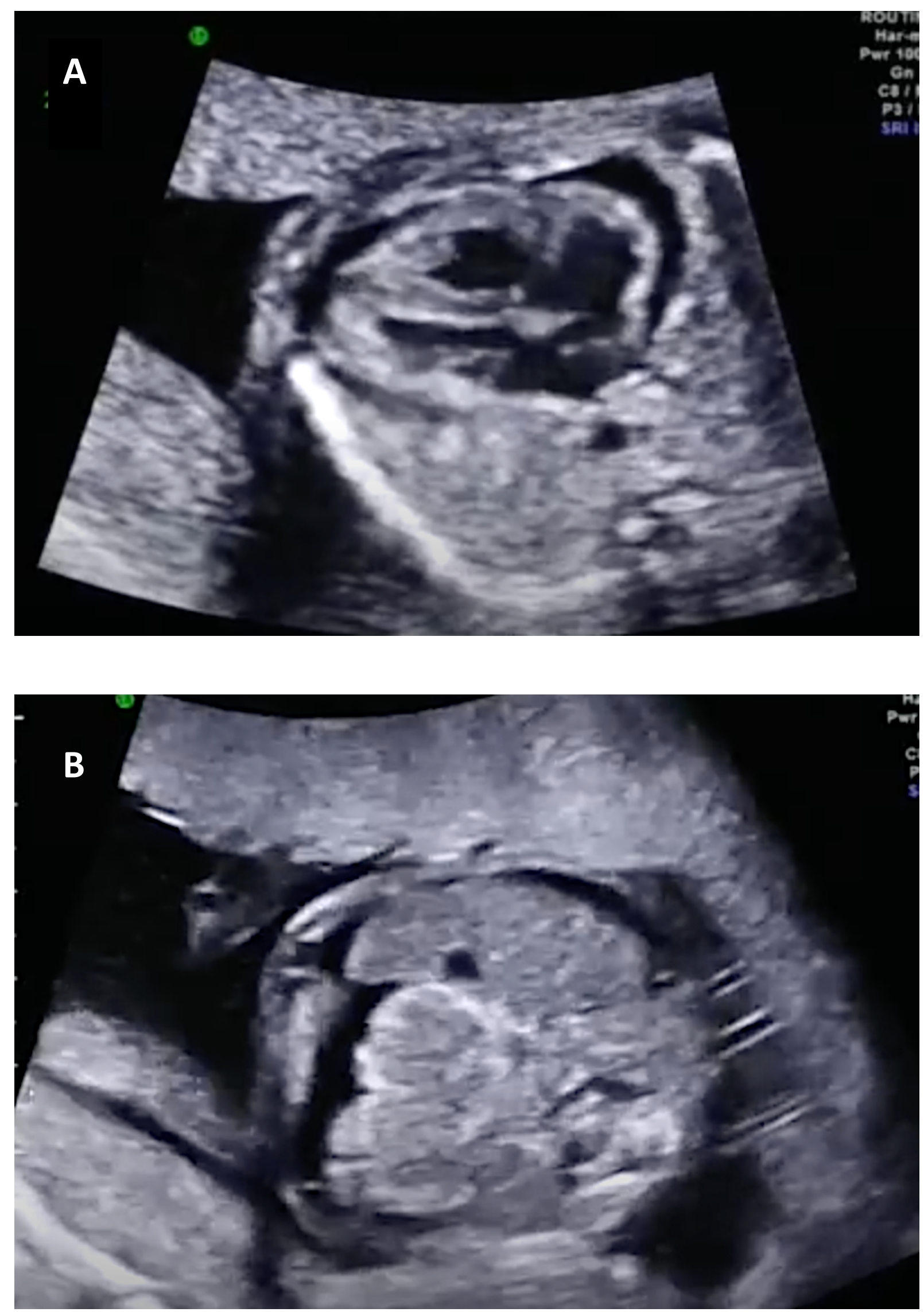

This article is protected by copyright. All rights reserved. 


\section{Tables}

Table 1 - Outcomes of congenital parvovirus B19 infections based on Bascietto et al. ${ }^{1}$

\begin{tabular}{|c|c|c|c|c|}
\hline \multirow{3}{*}{ Outcome } & \multicolumn{2}{|c|}{ Hydropic fetuses } & \multicolumn{2}{|c|}{ Non-hydropic fetuses } \\
\hline & Fetuses & Pooled \% & Fetuses & Pooled \% \\
\hline & (n) & $(95 \% C I)$ & (n) & $(95 \% C I)$ \\
\hline Miscarriage $(<20$ weeks $)$ & $16 / 53$ & $27.2(12.2-45.5)$ & $3 / 51$ & $8.8(2.8-17.6)$ \\
\hline Perinatal death & $98 / 372$ & $29.5(21.4-38.2)$ & $4 / 158$ & $4.4(1.2-9.7)$ \\
\hline Intrauterine death & $68 / 326$ & $24.0(16.4-32.5)$ & $3 / 158$ & $3.4(0.8-7.5)$ \\
\hline Neonatal death & $29 / 335$ & $3.1(0.2-8.1)$ & $1 / 104$ & $3.0(0.6-6.9)$ \\
\hline $\begin{array}{l}\text { Spontaneous resolution } \\
\text { infection }\end{array}$ & $17 / 314$ & $5.2(2.5-8.8)$ & $57 / 91$ & $49.6(20.7-78.6)$ \\
\hline Intrauterine transfusion & $218 / 271$ & $78.7(66.4-88.8)$ & $22 / 93$ & $29.61(6.0-61.6)$ \\
\hline Fetal loss after IUT & $53 / 188$ & $28.9(19.4-39.4)$ & $2 / 58$ & $5.5(1.2-12.5)$ \\
\hline Abnormal brain imaging & $7 / 63$ & $9.8(2.5-21.0)$ & $0 / 45$ & $0.0(0.0-7.0)$ \\
\hline $\begin{array}{l}\text { Abnormal } \\
\text { neurodevelopment }\end{array}$ & $7 / 70$ & $9.5(2.6-20.2)$ & $0 / 32$ & $0.0(0.0-7.5)$ \\
\hline
\end{tabular}




\section{University Library}

\section{- M M I E E R VA A gateway to Melbourne's research publications}

Minerva Access is the Institutional Repository of The University of Melbourne

Author/s:

Attwood, LO;Holmes, NE;Hui, L

Title:

Identification and management of congenital parvovirusB19infection

Date:

2020-09-30

Citation:

Attwood, L. O., Holmes, N. E. \& Hui, L. (2020). Identification and management of congenital parvovirusB19infection. PRENATAL DIAGNOSIS, 40 (13), pp.1722-1731. https:// doi.org/10.1002/pd.5819.

Persistent Link:

http://hdl.handle.net/11343/276375 